\title{
Ocorrência de fenótipos subnormais no limite Neoeifeliano/Eogivetiano, Tibagi, estado do Paraná: implicações tafonômicas e paleossinecológicas
}

Occurrence of subnormal size phenotype in the latest Eifelian/earliest Givetian boundary,

Tibagi city, Paraná State, Brazil: taphonomic and paleosynecologic implications

\author{
Elvio Pinto Bosetti \\ Rodrigo Scalise Horodyskill \\ Carolina Zabinill \\ Willian Mikio Kurita Matsumura ${ }^{\mathrm{V}}$ \\ Andressa Carla Penteadov
}

\begin{abstract}
Resumo: Registra-se aqui a ocorrência de fenótipos com dimensões subnormais de invertebrados marinhos fósseis na passagem Neoeifeliano/Eogivetiano (Devoniano). Estes fósseis representam uma fauna reliquiar, que é resultado de uma crise biótica ocorrida no período. Análises espećíicas foram efetuadas com o intuito de serem identificados possíveis tendenciamentos tafonômicos. De acordo com as assinaturas tafonômicas reconhecidas, é possível afirmar que os bioclastos não sofreram transporte significativo, podendo ser considerados como autóctones a parautóctones. A ocorrência de fenótipos com dimensões subnormais na Formação São Domingos não é resultado de tendenciamentos e as evidências obtidas espelham uma real resposta adaptativa de condições de estresse da síndrome pós-evento (Evento KACAK).
\end{abstract}

Palavras-chave: Devoniano. Província Malvinocáfrica. Formação São Domingos. Fenótipos subnormais de tamanho. Tafonomia.

\begin{abstract}
Subnormal size phenotype of marine invertebrates is recorded at the interval Neo-Eifelian/eo-Givetian (Devonian). These fossils represent a relictual fauna that resulted from a biotic crisis. Specific analysis were done to exclude the possibility of taphonomic bias. According with the taphonomic signatures obtained there was no significant bioclastic transport, and the taphocoenosis can be considered autochthonous to parautochthonous. The occurrence of subnormal size phenotype in the São Domingos Formation is not the result of bias and the data obtained evidences a real adaptative response for the stress conditions of the post-event syndrome (KACAK Event).
\end{abstract}

Keywords: Devonian. Malvinokaffric Realm. São Domingos Formation. Subnormal size phenotype. Taphonomy.

Universidade Estadual de Ponta Grossa. Departamento de Geociências. Ponta Grossa, Paraná, Brasil (elvio.bosetti@pq.cnpq.br).

Universidade Federal do Rio Grande do Sul. Porto Alegre, Rio Grande do Sul, Brasil (rodrigo.geo@gmail.com).

III Universidade Federal do Rio Grande do Sul. Porto Alegre, Rio Grande do Sul, Brasil (cazabini@gmail.com).

v Universidade Estadual de Ponta Grossa. Ponta Grossa, Paraná, Brasil (williammatsumura@gmail.com).

$\checkmark$ Universidade Estadual de Ponta Grossa. Ponta Grossa, Paraná, Brasil (acpenteado@gmail.com).

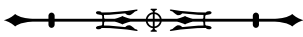




\section{INTRODUÇÃO}

A sucessão sedimentar siluro-devoniana (PridolianoFrasniano) ocorrente na região centro-leste do estado do Paraná (Figura 1) é composta pelas formações Furnas (Pridoliano-Lockoviano), Ponta Grossa (incluso o Membro Tibagi, Neopraguiano/Neoemsiano) e São Domingos (Eoeifeliano/Frasniano) (sensu Grahn et al., 2000; Gaugris \& Grahn, 2006; Mendlowicz Mauller et al., 2009). O registro dos folhelhos devonianos no Paraná consiste em depósitos sedimentares siliciclásticos em ambiente de mar epicontinental, de clima presumivelmente temperado, localizado entre $50^{\circ}$ e $60^{\circ}$ de paleolatitude sul à época da deposição. Atualmente, é interpretado como dominantemente episódico, onde os eventos deposicionais de maior magnitude ficaram preservados, caracterizados por depósitos de águas rasas, de fácies praial, e de águas mais profundas, de costa-a-fora (shoreface, transitional offshore e offshore).

A paleofauna da sucessão devoniana foi incluída no contexto de endemismo da Província Malvinocáfrica, introduzido por Richter (1941). A unidade litoestratigráfica de interesse do presente trabalho é a Formação São Domingos (Gaugris \& Grahn, 2006), correlata, em parte, às sequências Eifeliano-Frasniano (conforme a tese de doutorado de M. L. Assine, de 1996, intitulada "Aspectos da estratigrafia das sequências pré-carboníferas da Bacia do Paraná no Brasil") e sequências D e E (tese de doutorado de S. Bergamaschi, defendida em 1999 , cujo título é "Análise estratigráfica do Siluro-Devoniano (Formações Furnas e Ponta Grossa) da sub-bacia de Apucarana, Bacia do Paraná, Brasil”; Bergamaschi \& Pereira, 2001). Novos achados de fósseis representados por fenótipos subnormais de tamanho que caracterizam uma fauna reliquiar, remanescente de provável crise biótica, são registrados na área de estudo. O presente trabalho objetivou esclarecer se os tamanhos subnormais dos fósseis da área são produto de processo tafonômico ou se, de fato, a assembleia diminuta (Efeito Lilliput, de Urbanek, 1993) é resultado de uma crise biótica ocorrida durante um dos seis eventos globais de extinção do intervalo Eifeliano-Givetiano (KACAK Event).

\section{CONTEXTO GEOLÓGICO}

Lange \& Petri (1967) formalizaram a sucessão litoestratigráfica do Devoniano na bacia do Paraná (sub-bacia de Apucarana), propondo (da base para o topo) a Formação Furnas e a divisão tripartite da Formação Ponta Grossa, constituída pelos membros Jaguariaíva, Tibagi e São Domingos. Mais recentemente, Grahn et al. (2000), Gaugris \& Grahn (2006) e Mendlowicz Mauller et al. (2009) subdiviram o Devoniano da sub-bacia de Apucarana em três formações, denominadas, a partir da base, de Formações Furnas, Ponta Grossa (incluindo o Membro Tibagi) e São Domingos. Esta é a nomenclatura litoestratigráfica utilizada no presente trabalho. A Formação São Domingos, unidade de interesse da presente pesquisa, é constituída por uma sucessão de folhelhos laminados de cor cinza, às vezes betuminosos, com intercalações de delgadas camadas de arenitos finos a grossos. Esta unidade documenta uma inundação em ampla escala, que fecha o registro devoniano pré-'struniano' da sinéclise. Os folhelhos givetianos representam uma expansão do sítio deposicional, sendo o registro do pico máximo de transgressão no Devoniano da bacia do Paraná. Milani et al. (2007) afirmam ainda que, na passagem Eifeliano-Givetiano, um episódio de expansão marinha teria promovido uma conexão entre as bacias do Paraná e Parnaíba, evidenciada paleontologicamente por macrofósseis e palinomorfos.

\section{MATERIAL E MÉTODOS}

O material paleontológico provém do afloramento Sítio Wolff, localizado na região do Barreiro, Tibagi, Paraná (24 33’ 42” S - 50॰31'00” W) (Figura 1), e encontrase depositado no Laboratório de Paleontologia, do Departamento de Geociências, da Universidade Estadual de Ponta Grossa, sob as siglas DEGEO/MPI-3230 a DEGEO/MPI-3930, totalizando 700 amostras, cada uma delas contendo um ou mais fósseis. 


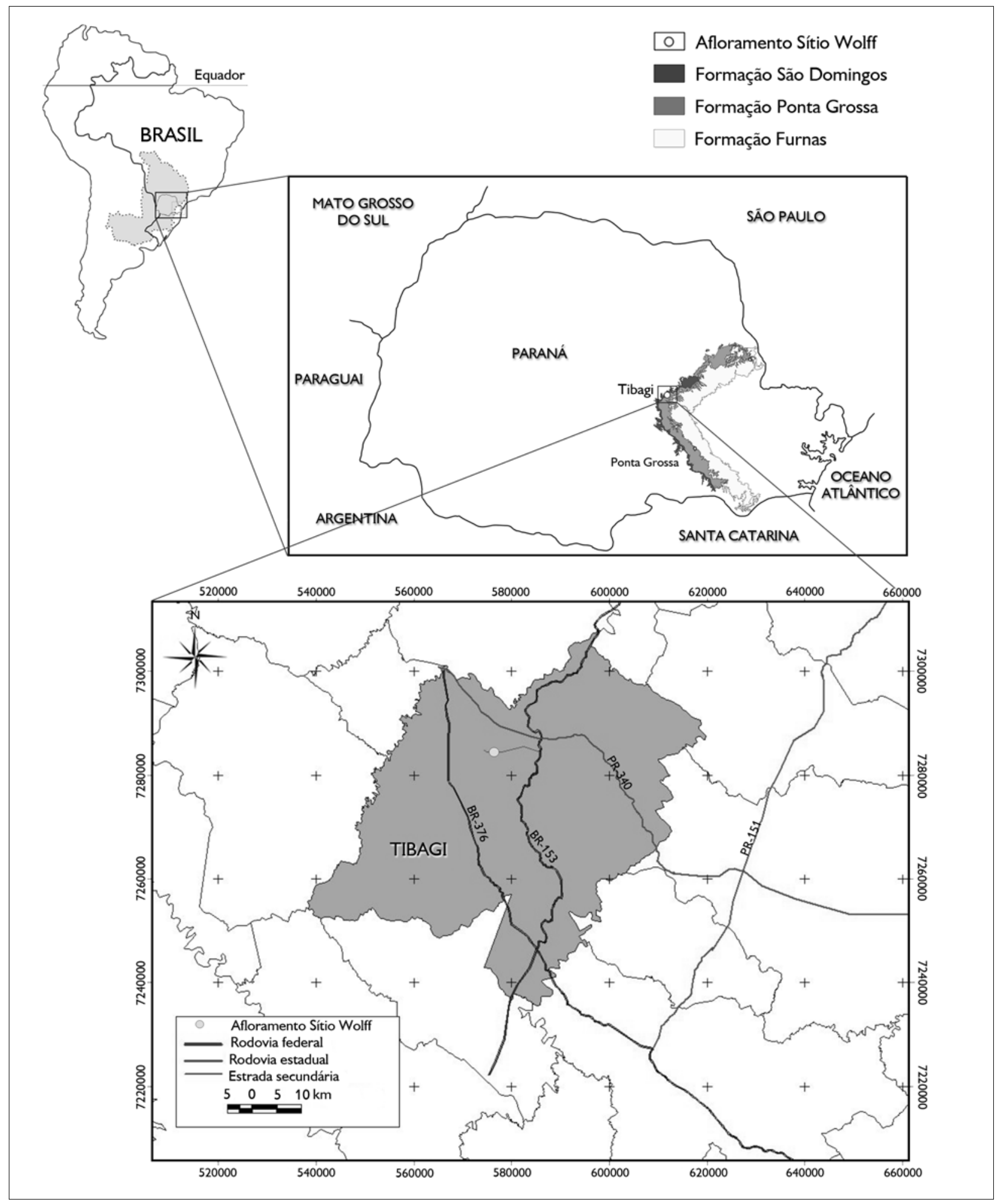

Figura 1. Mapa de localização do afloramento Sítio Wolff, borda leste da bacia do Paraná, Tibagi, estado do Paraná.

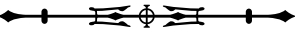


Os trabalhos de campo seguiram o protocolo tafonômico/paleoautoecológico proposto por Simões \& Ghilardi (2000).

RESULTADOS: GEOLOGIA E PALEONTOLOGIA A região do Barreiro, localizada no bairro São Domingos, no município de Tibagi (Figura 1), juntamente com a área de Lambedor (Arapoti) são as únicas regiões de afloramentos do Devoniano paranaense ainda pouco exploradas. Com exceção de Petri (1948), Lange \& Petri (1967), Lange (1967), Bosetti et al. (2009) e Bosetti et al. (2010), da dissertação de mestrado de J. H. G. Melo, de 1985, intitulada "A Província Malvinocáfrica no Devoniano do Brasil" e da tese de doutorado de E. P. Bosetti, de 2004, "Tafonomia de alta resolução das fácies de offshore da sucessão devoniana da região de Ponta Grossa - Paraná, Brasil", as referências a essas camadas raramente são feitas com base em dados de campo obtidos diretamente nessa região. No entanto, os folhelhos São Domingos atingem, em superfície, seu melhor desenvolvimento na própria área-tipo. O ponto de coleta denominado Sítio Wolff encontra-se estratigraficamente posicionado na porção média da coluna da Formação São Domingos, na passagem do Neoeifeliano/Eogivetiano (Bosetti et al., 2010). Neste ponto, foram encontrados os bioclastos, muitos dos quais são representantes do Domínio Malvinocáfrico, que evidenciaram fenótipos subnormais, conforme já registrado por Bosetti et al. (2009, 2010). O afloramento Sítio Wolff encontra-se estratigraficamente acima dos arenitos médios a grossos e abundantemente fossiliferos do Membro Tibagi aflorantes na mesma região (Figura 2).

O pacote apresenta espessura de 20,5 m de sedimentos, cuja base é composta por uma camada de 6 $m$ de arenitos mal selecionados, que variam de médios a grossos, maciços, com níveis conglomeráticos, contendo seixos de quartzo e quartzito, cujos diâmetros são sempre inferiores a $1 \mathrm{~cm}$. Essas camadas são aparentemente afossiliferas. Como capeamento dos arenitos, ocorre um intervalo de $2 \mathrm{~m}$ de siltitos e folhelhos sílticos bioturbados, com fragmentos de vegetais não identificados dispostos paralelos ao plano de acamamento. Na porção média, ocorrem $5 \mathrm{~m}$ de folhelho preto, muito litificado, sem qualquer vestígio de macrofósseis, microfósseis ou bioturbação. Sobrepostos a essa fácies, recorrem os mesmos arenitos conglomeráticos da base em uma espessura que não ultrapassa $0,5 \mathrm{~m}$. No topo da seção, foram registrados $2 \mathrm{~m}$ de folhelhos sítticos, muito litificados, micáceos, de coloração amarelo-ocre, intensamente fraturados, cerosos, e uma sucessão de $5 \mathrm{~m}$ de siltitos médios a grossos também fraturados; ambas as fácies são abundantemente fossilíferas.

Nos folhelhos, foi registrada (em ordem de abundância) a presença de icnofósseis (Phycosiphon), fragmentos de Spongiophyton e vegetais não identificados, fragmentos de conulários, braquiópodes lingulídeos, trilobites calmoniídeos, braquiópodes rinconeliformes, crustáceos ostracodes e moluscos bivalves (Figuras 3 e 4).

Nos siltitos de topo, foi registrada (também em ordem de abundância) a presença de icnofósseis (Phycosiphon) e traços fósseis caracterizados por marcas de rolamento (roll marks), possivelmente produzidas por cefalópodes de concha espiralada (e.g. Seilacher, 2007, pl. 57), fragmentos de Spongiophyton e vegetais não identificados, trilobites calmoniídeos, fragmentos de conulários, crustáceos ostracodes e braquiópodes lingulídeos (Figuras 3 e 4).

Uma particularidade de todos os bioclastos encontrados nesses pacotes, bem como dos icnofósseis, são suas pequenas dimensões, quando comparadas às demais ocorrências dos mesmos taxa em fácies da Formação Ponta Grossa e da base da Formação São Domingos (conforme demonstrado na Figura 5). Apesar do tamanho diminuto, todos os taxa coletados apresentam características morfoanatômicas de estágio ontogenético avançado (costelas, linhas de crescimento, forma do listrium e o número de somitos foram considerados no estudo de cada grupo), ou seja, são representantes de formas adultas e foram taxonomicamente identificados conforme a Tabela 1. 


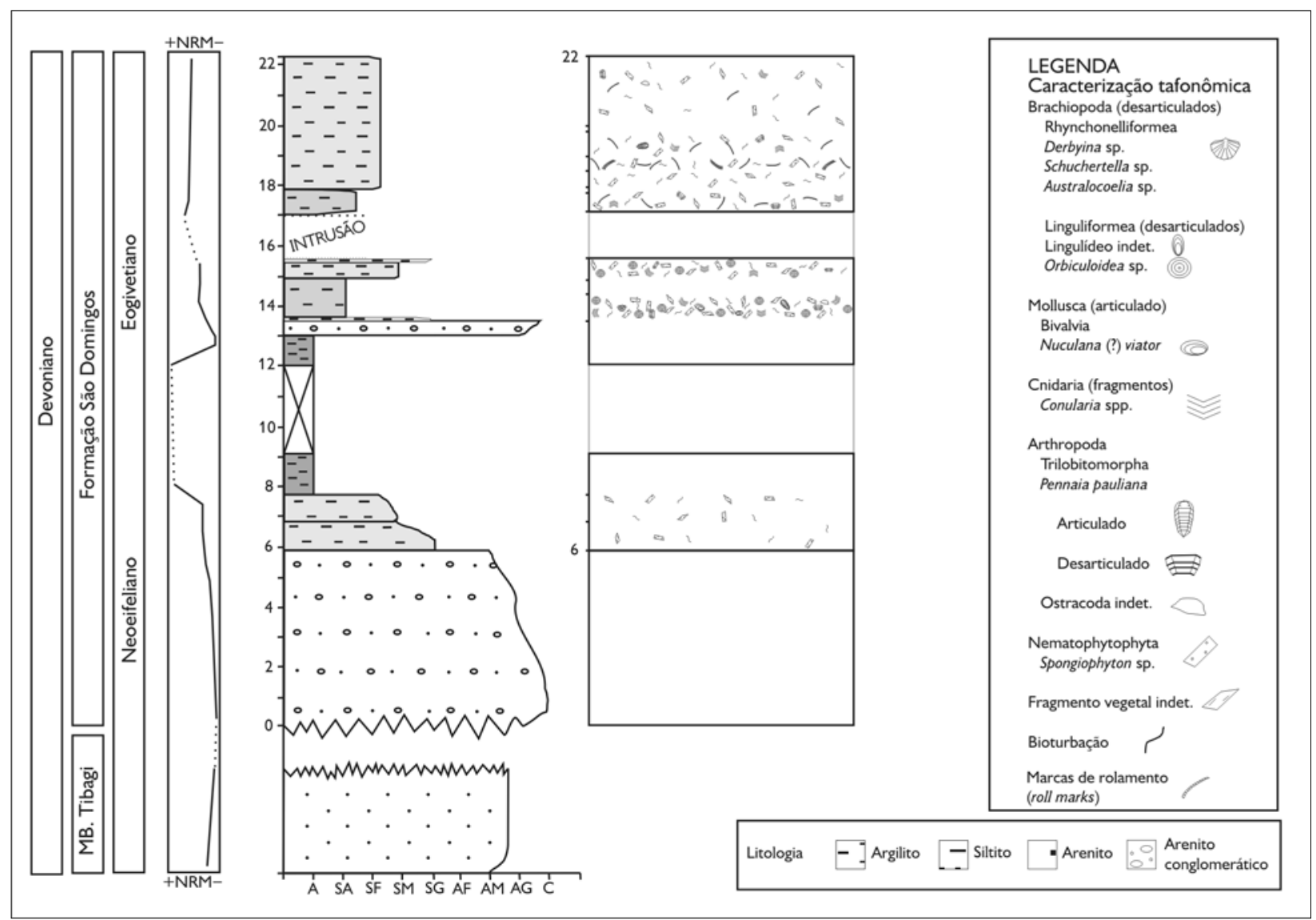

Figura 2. Seção colunar do afloramento Sítio Wolff e as distribuições taxonômicas e tafonômicas.

A distribuição vertical dos bioclastos em níveis de ocorrência e abundância é controlada pelas variações litológicas e, portanto, eles não se encontram randomicamente distribuídos pela seção perfilada (Figura 3).

A análise tafonômica foi efetuada procurando-se identificar os seguintes atributos: a) graus de fragmentação de valvas; b) graus de desarticulação de valvas e peças; c) posição das valvas e peças em relação ao plano de acamamento; d) graus de bioerosão; e) graus de abrasão; f) grau de empacotamento; g) níveis de distribuição e abundância. Conforme a Tabela 2, os conulários apresentam-se muito fragmentados; braquiópodes e moluscos apresentam-se inteiros, com exceção de um exemplar de Schuchertella agassizi Hartt, 1874, parcialmente fragmentado. Os trilobites apresentam baixo grau de desarticulação, representados por espécimes inteiros e com articulação tórax/pigídio. Pigídios e céfalos isolados são subordinadamente registrados. Com exceção de Spongiophyton, os vegetais são de difícil classificação. Não foram encontrados exemplares apresentando bioerosão e abrasão. O grau de empacotamento dos bioclastos pode ser classificado como fracamente empacotado, suportados pela matriz.

\section{DISCUSSÃO}

\section{SOBRE OS TENDENCIAMENTOS TAFONÔMICOS}

Variações morfológicas e fenótipos aparentemente subnormais devem ser analisados com muito critério, uma vez que os processos de preservação dos fósseis, sobretudo a

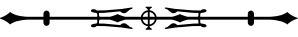




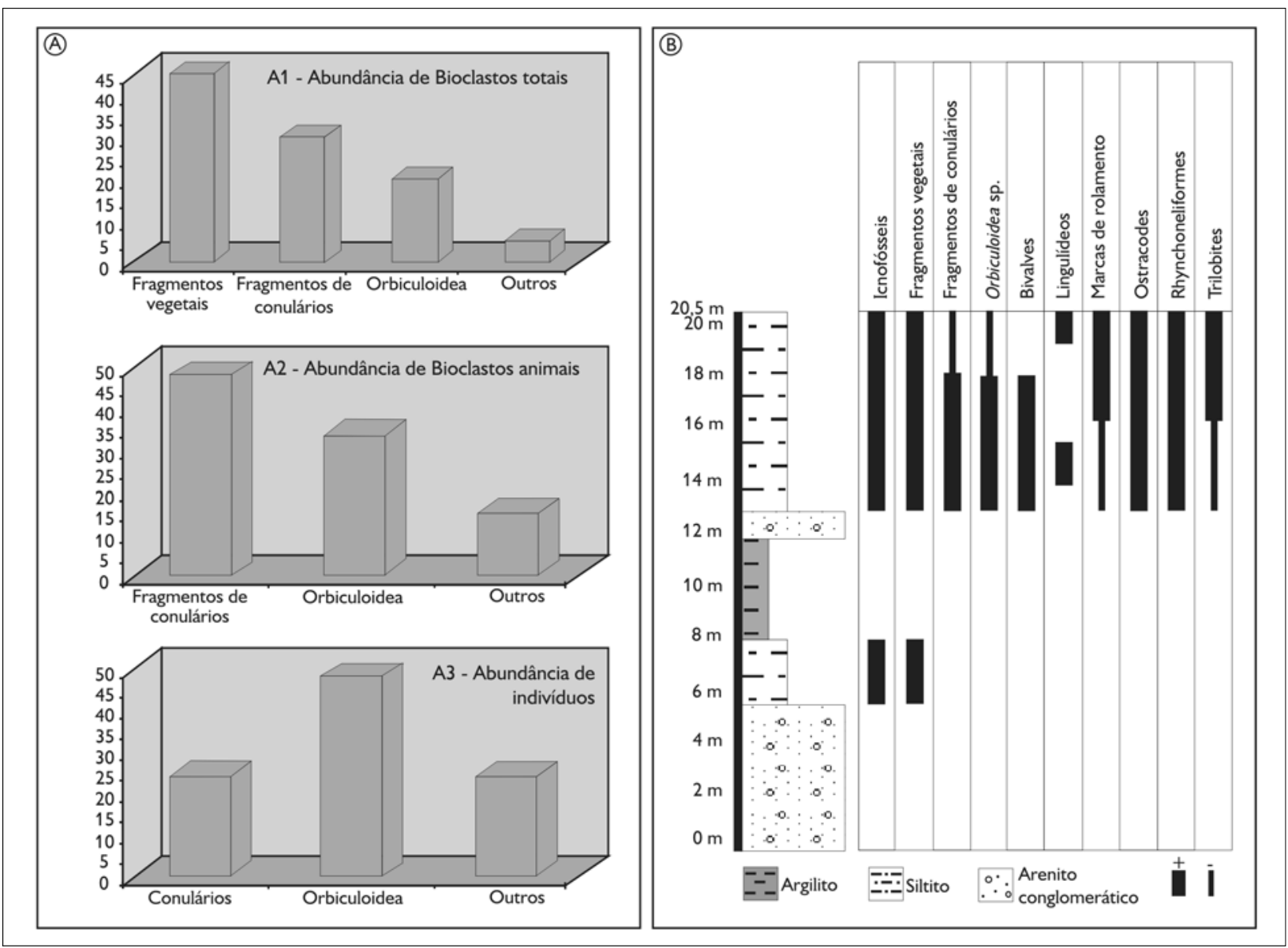

Figura 3. (A1) Gráfico de abundância de bioclastos totais; (A2) gráfico de abundância de bioclastos animais; (A3) gráfico de abundância de indivíduos; (B) ocorrência e distribuição dos bioclastos nas diferentes litologias do afloramento Sítio Wolff, Tibagi, Paraná.

fossildiagênese, podem afetar a morfologia original dos bioclastos. Lucas (2001) introduziu na literatura o termo taphotaxa, em alusão aos taxa erigidos com base em caracteres morfológicos que são fruto de alterações produzidas pelo processo de fossilização. Simões et al. (2003) e Soares et al. (2008) identificaram taxa inválidos descritos da fauna da sucessão devoniana (conulários e trilobites, respectivamente), demonstrando como as alterações diagenéticas e intempéricas podem modificar as estruturas originais dos fósseis, levando a erros em suas classificações taxonômicas.

Os fenótipos de tamanho subnormal foram descritos e comparados aos de dimensões normais encontrados em outras fácies. Alterações morfológicas ligadas aos aspectos tafonômicos não foram observadas, e todos os fósseis apresentam linhas de crescimento, estrias, peças e morfologia das valvas e exúvias indicando avançado estágio ontogenético.

Segundo Twichett (2007), em relação ao tamanho dos espécimes, alguns aspectos preservacionais podem afetar a totalidade de fósseis de uma assembleia, e a seleção hidrodinâmica dos bioclastos (por algum tipo de fluxo energético) é um dos fatores a serem considerados na checagem de tendenciamentos tafonômicos. No presente caso, há ocorrência de fósseis inteiros e fragmentos de tamanhos variados numa mesma amostra de mão e nos mesmos pavimentos. Fragmentos vegetais muito tênues estão associados a carcaças de trilobites inteiros 


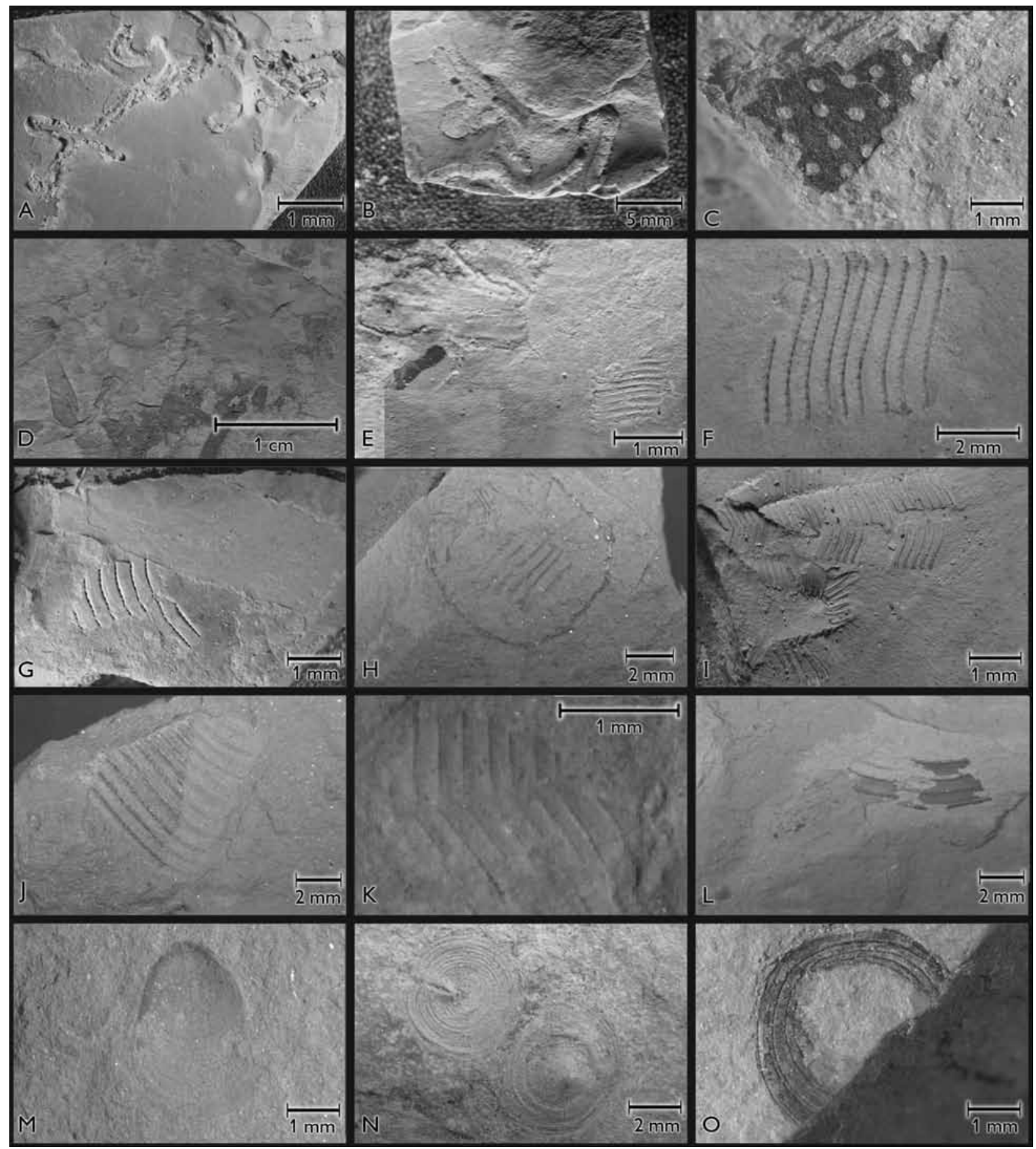

Figura 4. (A) Icnofóssil ?Phycosiphon sp.; (B) Icnofóssil ?Phycosiphon sp.; (C) Fragmento de Spongiophyton sp.; (D) Fragmentos vegetais não identificados; (E) Fragmento de Conularia spp. associado à fragmento vegetal; (F) Fragmento de Conularia spp.; (G) Fragmento de Conularia spp. com fragmento de Spongiophyton; (H) Fragmento de Conularia spp.; (I) Conularia spp.; (J) Fragmento de Conularia spp.; (K) Fragmento de Conularia spp.; (L) Fragmento de Conularia spp. associado com fragmento vegetal; (M) Braquiópode Lingulídeo indet preservado no plano de acamamento; (N) Braquiópode Orbiculoidea baini (valva pedicular à direita e braquial à esquerda) preservado no plano de acamamento; $(\mathrm{O})$ Braquiópode Orbiculoidea excentrica fragmentada na coleta 


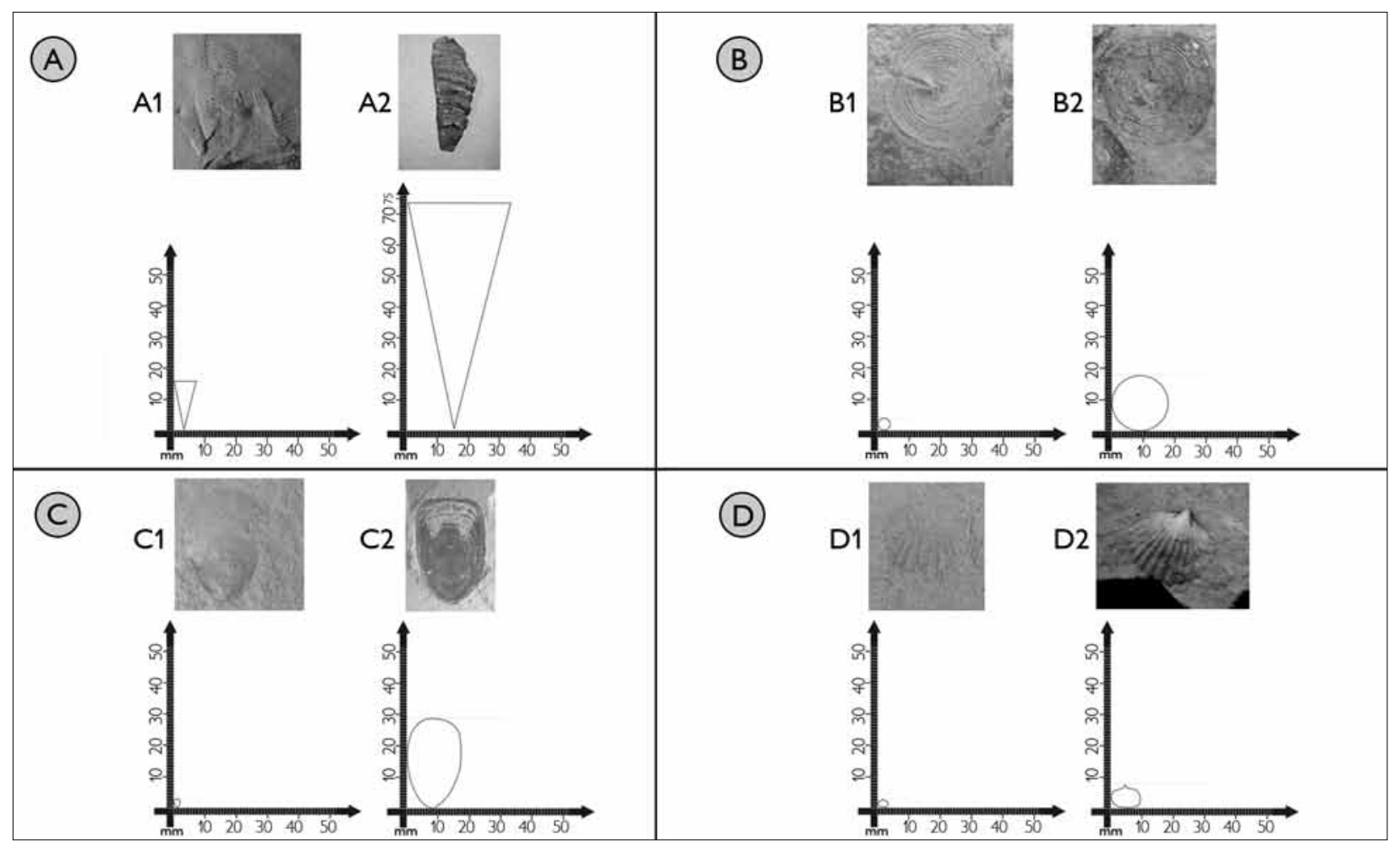

Figura 5. Gráficos que demonstram os fenótipos subnormais dos fósseis do afloramento Sítio Wolff, em comparação aos fenótipos normais da Formação Ponta Grossa e base da Formação São Domingos: (A) Conularia spp.; (B) Orbiculoidea baini; (C) Lingulídeo indet.; (D) Australocoelia sp. A1, B1, C1 e D1 representam espécies de fenótipos subnormais; A2, B2, C2 e D2 representam as mesmas espécies com tamanhos normais. Note que a redução de tamanho em alguns casos pode atingir a cifra de até $90 \%$.

e a orbiculóides de dimensões quase imperceptíveis a olho nu, todos com dimensões e densidades diferentes, mas ocorrendo lado-a-lado. Isto sugere que, se houve transporte dos bioclastos, este não foi suficiente para promover a seleção por tamanho ou densidade.

Classes tafonômicas vinculadas à paleobatimetria e a graus de autoctonia/parautoctonia/aloctonia foram propostas por Rodrigues et al. (2003) para os conulários, e por Simões et al. (2009) para os trilobites homalonotídeos. Para os conulários ocorrentes no Sítio Wolff, foi identificada a classe tafonômica 3-IV de Rodrigues et al. (2003), que é representada por conulários isolados e horizontalmente orientados no plano de acamamento, incompletos e faltando a região da abertura, ocorrendo em siltitos bioturbados (índice de bioturbação 3 de Miller \& Smail, 1997) no nível de base de ondas de tempo bom (NBOTB). Se considerada a tafonomia dos conulários, a tafocenose apresenta-se de parautóctone a alóctone.

Quanto aos graus de desarticulação e fragmentação, considerou-se a anatomia básica dos grupos taxonômicos registrados, pois se trata de uma fauna variada com morfologias obviamente distintas. Todas as valvas de braquiópodes rinconeliformes e moluscos bivalves estão desarticuladas e paralelas ao plano de acamamento. Este padrão sugere que algum tempo ocorreu entre a morte destes organismos e seu soterramento final, porém sem seleção hidrodinâmica. Quanto aos trilobites, três situações foram observadas: um registro predominante de preservação completa das exúvias (carcaça estendida), seguida por preservação de articulação tórax/pigídio. De forma subordinada, ocorrem pigídios isolados e, mais

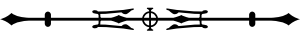


Tabela 1. Taxonomia dos invertebrados fósseis ocorrentes no afloramento Sítio Wolff, Tibagi, Paraná.

\begin{tabular}{|c|c|c|}
\hline CNIDARIA & CONULATAE & Conularia sp. Sowerby, 1820 \\
\hline \multirow{3}{*}{ BRACHIOPODA } & DISCINIDAE & $\begin{array}{c}\text { Orbiculoidea baini Sharpe, } 1856 \\
\text { Orbiculoidea excentrica Lange, } 1943\end{array}$ \\
\hline & LINGULIDAE & Lingulídeos infaunais indet. \\
\hline & RHYNCHONELIDAE & $\begin{array}{c}\text { Derbyina whitiorum Clarke, } 1913 \\
\text { Australocoelia sp. Boucot \& Gill, } 1956 \\
\text { Schuchertella agassizi Hartt, } 1874\end{array}$ \\
\hline MOLLUSCA & BIVALVIA & Nuculana? viator Reed, 1925 \\
\hline \multirow{2}{*}{ ARTHROPODA } & TRILOBITA & Pennaia pauliana Clarke, 1913 \\
\hline & CRUSTACEA & Ostracoda indet. \\
\hline ICNOFÓSSEIS & $\begin{array}{l}\text { ICNOFÁCIES } \\
\text { ZOOPHYCOS }\end{array}$ & $\begin{array}{l}\text { Phycosiphon sp. } \\
\text { roll marks }\end{array}$ \\
\hline NEMATOPHYTOPHYTA & SPONGIOPHYTACEAE & Spongiophyton spp. Kräusel, 1954 \\
\hline ALGAS & $?$ & $?$ \\
\hline
\end{tabular}

Tabela 2. Dados tafonômicos dos bioclastos ocorrentes no afloramento Sítio Wolff: F - fragmentado; MF - muito fragmentado; I - inteiro; D - desarticulado; A - articulado; PA - no plano de acamamento; FP - fora do plano de acamamento; X - dado não diagnosticado.

\begin{tabular}{c|c|c|c}
\hline Táxon & Fragmentação & Articulação & Posição \\
\hline Conularia sp. & MF & $\times$ & PA \\
\hline Orbiculoidea baini & $\mathrm{I}$ & $\mathrm{D}$ & PA \\
\hline Orbiculoidea excentrica & $\mathrm{I}$ & $\mathrm{D}$ & PA \\
\hline Lingulídeo indet. & $\mathrm{I}$ & $\mathrm{D}$ & PA \\
\hline Derbyina whitiorum & $\mathrm{I}$ & $\mathrm{D}$ & PA \\
\hline Australocoelia sp. & $\mathrm{I}$ & $\mathrm{D}$ & PA \\
\hline Schuchertella agassizi & $\mathrm{F}$ & $\mathrm{D}$ & PA \\
\hline Nuculana? viator & $\mathrm{I}$ & $\mathrm{DeA}$ & PA \\
\hline Pennaia pauliana & $\mathrm{X}$ & $\mathrm{A}$ & PA \\
\hline Ostracoda indet. & $\mathrm{I}$ & $\times$ & PA/FP \\
\hline Phycosiphon isp. & $\mathrm{X}$ & $\times$ & PA \\
\hline Spongiophyton spp. & $\mathrm{F}$ & $\times$ & PA \\
\hline Algas indeterminadas & $\mathrm{MF}$ & & \\
\hline
\end{tabular}

raramente, céfalos isolados, o que foi interpretado como situação de autoctonia a parautoctonia (Figura 6).

Braquiópodes discinídios são muito abundantes e representados exclusivamente pelo gênero Orbiculoidea. Não foi observado o típico achatamento dorso-ventral nas valvas braquiais, pois estas apresentam sua forma cônica original. É comum a ocorrência de valvas braquiais e pediculares desarticuladas, porém próximas e, em alguns casos, tratando-se de mesmo indivíduo. Lingulídeos infaunais apresentam-se paralelos ao plano de acamamento, 


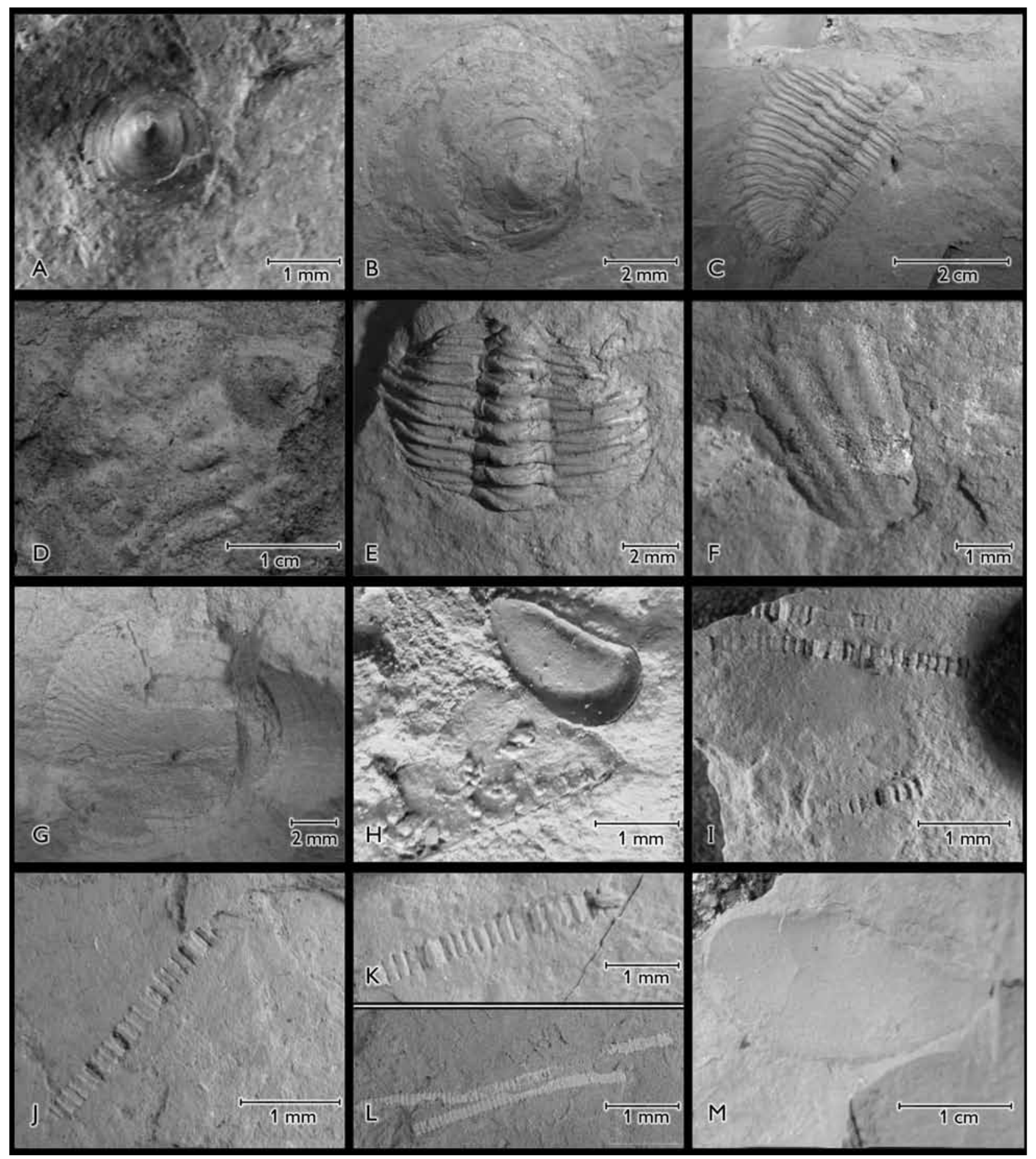

Figura 6. (A) Braquiópode Orbiculoidea baini (valva braquial sem achatamento dorsoventral); (B) Braquiópode Orbiculoidea excentrica; (C) Carcaça estendida de trilobite Pennaia pauliana, céfalo fragmentado na coleta; (D) Céfalo de trilobite Pennaia pauliana; (E) Tórax de trilobite Pennaia pauliana; (F) Braquiópode Australocoelia sp.; (G) Schuchertella agassizi pouco fragmentada; $(H)$ Crustácea Ostracoda no plano de acamamento; (I) marcas de rolamento (roll marks); (J) marcas de rolamento (roll marks); (K) marcas de rolamento (roll marks); (L) marcas de rolamento (roll marks); (M) Bivalvia Nuculana? viator no plano de acamamento.

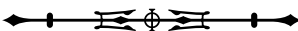


inteiros ou com as valvas em tesoura, demonstrando que não houve significativo transporte destes espécimens, podendo considerá-los como autóctones a parautóctones.

Cefalópodes são relativamente raros na sucessão devoniana do estado do Paraná, onde dois gêneros de ortoceratídeos são registrados (Orthoceras e Spyroceras). Além destes, Bosetti et al. (2010) registraram, com dúvida, cefalópodes ortoceratídeos do gênero Ctenoceras Noetling, 1884 na área em estudo. Este material é composto por impressões e moldes, delineando câmaras nítidas. No entanto, a falta de extremidades (inclusive a apical), a presença de curvaturas diferentes entre si, associadas a formas retas, e espessuras que variam ao longo do comprimento da concha são atributos que parecem não evidenciar a presença de um bioclasto, e sim de um traço fóssil. Estruturas semelhantes são referidas por Seilacher (2007), que ilustra marcas de rolamento (roll marks) produzidas por cefalópodes espiralados nos folhelhos de Solnhofen, Alemanha. Esta ocorrência inédita deverá ainda ser objeto de estudo mais detalhado.

Icnofósseis referidos ao icnogênero Phycosiphon (icnofácies Zoophycos) estão dispostos como laços em forma de $U$ e que, em grande número, originam sistemas maiores, dispondo-se de modo paralelo ou levemente oblíquo em relação ao plano de acamamento.

Pelo conjunto de dados resultantes da análise tafonômica básica, pode-se concluir que a tafocenose é autóctone a parautóctone, ou seja, situa-se próximo ao sítio de vida, sendo o transporte nulo ou pouco significativo.

\section{SOBRE A EXTINÇÃO DA FAUNA MALVINOCÁFRICA}

Em oposição às entidades zoogeográficas contemporâneas que dominavam os mares rasos de águas mais aquecidas do hemisfério norte e da Oceania, a Província Malvinocáfrica caracterizou-se por apresentar uma baixa diversidade faunística, onde relativamente poucos taxa seriam bem representados por numerosos indivíduos com ampla dispersão regional (Shirley, 1965). Esta província também se distinguiu por incluir certos gêneros de braquiópodes e de trilobites que são desconhecidos ou mal representados nos conjuntos faunísticos contemporâneos do hemisfério norte. A extinção dessa fauna na bacia do Paraná é assunto ainda muito polêmico, tanto em relação aos fatores ambientais físicos quanto em relação à geocronologia.

Copper (1977) sugere uma extinção em massa da fauna na passagem Frasniano-Fameniano, baseado na hipótese de que um clima radicalmente frio teria causado a extinção da fauna recifal e perirrecifal. Isaacson (1978) contesta o trabalho de Copper (1977), afirmando que a extinção ocorreu em função de uma acentuada regressão marinha no final do Devoniano. Em sua dissertação de mestrado, J. H. G. Melo não reconhece formas malvinocáfricas na seção superior do sistema Devoniano preservado atualmente na bacia do Paraná, mas admite uma expansão temporal da fauna com índices muito baixos de ocorrência até o Givetiano. Para Assine \& Petri (1996), a transgressão ocorrida na passagem Eifeliano-Givetiano acarretou uma mudança ecológica drástica, responsável pelo desaparecimento da fauna. E. P. Bosetti, em sua tese de doutorado, descreveu parte da Formação São Domingos na região do Barreiro, e seus achados evidenciaram a presença de uma fauna de trilobites calmoniídeos, conulários e braquiópodes rinconeliformes, todos supostamente extintos nessa época de deposição (Figuras 4 e 6). O registro indicou que a fauna malvinocáfrica ultrapassara os limites do Givetiano, chegando ao topo da sequência local sem aparente modificação em sua paleobiodiversidade. No entanto, novos achados da mesma região, relatados em Bosetti et al. (2009), na dissertação de mestrado de R. S. Horodyski, de 2010, cujo título é "Tafonomia dos invertebrados fósseis na sequência Eifeliana/Frasniana da sucessão devoniana da sub-Bacia de Apucarana, Bacia do Paraná, Tibagi-PR, Brasil" e Bosetti et al. (2010), demonstraram que apenas alguns grupos ultrapassaram esse limite e, assim mesmo, eles possuem morfologia subnormal quando comparados aos típicos invertebrados malvinocáfricos. 
É consenso, na literatura especializada, que o topo do Devoniano da bacia do Paraná, no estado homônimo, é pouco fossilífero, onde grande parte dos invertebrados ocorrentes na base e porção média do Devoniano teria sido extinta antes da deposição dos pacotes superiores. Boa parte destes pacotes foi depositada em condições de maior profundidade, pois reflete um pico de transgressão ocorrida ao final do Devoniano. A sugestão de que a quase totalidade dos afloramentos do 'autêntico' folhelho São Domingos, no estado do Paraná, é muito pobre em macrofósseis (exceção feita a restos vegetais fragmentados e icnofósseis) é contestada pelos novos achados relatados por E. P. Bosetti na tese de doutoramento, por Bosetti et al. (2009, 2010), por R. S. Horodyski, na dissertação de mestrado, e pelo registro desta assembleia reliquiar da fauna malvinocáfrica nos folhelhos São Domingos.

\section{SOBRE OS FENÓTIPOS SUBNORMAIS}

$\mathrm{O}$ aparecimento de assembleias fósseis reliquiares é comum no registro paleontológico mundial, principalmente naqueles que representam momentos imediatos pósextinção (por exemplo, Ireviken Event, Siluriano da Suécia (Erlfeldt, 2005); Trangrediens Event, limite SiluroDevoniano do leste europeu (Urbanek, 1993); EndPermian Event (Twichett, 2007). Urbanek (1970) define as assembleias reliquiares como complexos de espécies de baixa diversidade ou ocorrências monoespecíficas sobreviventes a distúrbios ambientais de uma determinada área. É o efeito imediato pós-extinção, associado a cada crise biótica, que conduz à drástica redução no número de espécies como resultado de ação ecológica. Esta, por sua vez, abre possibilidades de novas espécies ocuparem o local afetado via especiação ou imigração. Urbanek (1993) salienta que, em alguns casos, as assembleias reliquiares exibem atributos de síndrome pós-evento e apresentam algumas características, como baixa diversidade extrema, grande abundância de indivíduos e fenótipos subnormais, devido à aparente redução do tamanho.
As concentrações fossiliferas que são objeto deste trabalho podem ser consideradas como representantes de assembleias reliquiares, pois tal qual a fauna malvinocáfrica típica, a fauna encontrada na localidade denominada Sítio Wolff apresenta-se com baixa diversidade taxonômica e grande abundância numérica (Figura 3). O fator distintivo destas novas concentrações é que a diversidade é ainda menor do que aquela que caracteriza o endemismo malvinocáfrico, e os níveis de abundância de cada taxon são também muito altos. $\bigcirc$ fato das formas adultas dos fósseis encontrados nesta localidade apresentarem dimensões de carapaças e peças muito menores do que o normal (Figura 6) e a presença de icnofósseis nunca antes registrados (Figura 6) nessas camadas (imigração dos produtores?) sugerem que as condições estabelecidas por Urbanek $(1970,1993)$ estão presentes nestas fácies da Formação São Domingos.

Adicionalmente, os níveis estratigráficos prospectados são supostamente aqueles depositados após a extinção da fauna malvinocáfrica. Todos estes atributos somados conferem a esta concentração um status de fauna reliquiar da Província Malvinocáfrica. Demais invertebrados associados, incluindo os fenótipos de tamanhos subnormais e icnitos inéditos, são, em conjunto, resultado da síndrome pós-evento.

\section{SOBRE OS PALEOAMBIENTES E A PALEOSSINECOLOGIA}

A variação litológica observada na área perfilada foi regida por variações eustáticas drásticas, se consideradas as modestas variações litológicas de grande parte da Formação Ponta Grossa. Esse empilhamento indica uma sucessão de paleoambientes expressos num padrão de sedimentos grossos, para shoreface, a finos, para offshore, segundo nomenclatura de Walker \& Plint (1992) e Reading \& Collinson (1996). Assim, os paleoambientes inferidos para a seção vão desde shoreface proximal até offshore distal. A base é representada por um acentuado processo regressivo, com a presença de arenitos muito grossos, conglomeráticos, evidenciando um ambiente de shoreface proximal, sem nenhum vestígio de fóssil. Acima, um

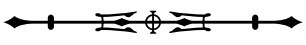


nível granodecrescente é composto por uma sucessão de arenitos finos a siltitos médios contendo icnofósseis (Phycosiphon) e fragmentos vegetais não identificados, culminando com um folhelho argiloso preto, estéril em macrofósseis, indicando um processo retrogradacional, de ambiente de offshore distal, abaixo do nível de base ondas de tempestade (NBOT). Em direção ao topo, uma delgada camada de arenitos conglomeráticos semelhante à base é novamente registrada, representando um repentino retorno da fácies praial (shoreface proximal). Capeando este pacote, registram-se folhelhos sílticos recobertos por siltitos finos a grossos, contendo marcas onduladas, espelhando ambientes de shoreface distal, próximo ao nível de base de ondas de tempo bom (NBOTB). Estas últimas fácies são abundantemente fossilíferas e detentoras dos fenótipos subnormais. A distribuição e a abundância dos fósseis na seção não são aleatórias e estão estreitamente vinculadas aos ambientes deposicionais reconhecidos, conforme pode ser observado na Figura 3B.

A fauna malvinocáfrica e os demais invertebrados que povoaram os mares epicontinentais durante o Devoniano na bacia do Paraná foram sujeitos a barreiras ecológicas efetivas e, por este motivo, a fauna apresenta alto grau de endemismo em quase todos os grupos taxonômicos. Essa situação, por si só, gerou uma assembleia fossilífera com baixa biodiversidade e grande número de indivíduos. Sob esta óptica, a fauna devoniana da bacia do Paraná coexistiu em constante estresse ecológico, sendo perturbada ocasionalmente pela imigração de outros taxa, quando prováveis ligações com outras bacias foram possíveis devido a picos transgressivos.

Das conjecturas acima, pode-se inferir que a fauna reliquiar aqui enfocada é a representação de um momento crítico da fauna malvinocáfrica, e que os demais invertebrados associados sofreram impactos devido a uma intensa mudança ambiental com as rápidas elevações do nível do mar ocorridas no Devoniano médio. Crises bióticas (alteração dos níveis de oxigenação, temperatura e disponibilidade de nutrientes) podem ter sido as responsáveis pelo declínio da fauna original já bem adaptada. O intervalo imediato de pós-extinção, denominado por Urbanek (1970) de Síndrome pós-Evento, é o responsável pelo surgimento no registro geológico de assembleias reliquiares, normalmente apresentando fenótipos subnormais de tamanho nos sobreviventes.

No perfil em estudo, foi possível identificar pelo menos três grandes mudanças batimétricas e, consequentemente, de temperatura e oxigenação. A base do perfil representa situação de fácies praial e a ausência de bioclastos pode ser explicada pela tafonomia, uma vez que a preservação de fósseis em arenitos grossos conglomeráticos é mais difícil de ocorrer. A porção média representa um momento de afogamento máximo do sistema e o pico mais elevado da transgressão local. $O$ fato de nenhum bioclasto e nenhum icnofóssil ter sido encontrado nestas fácies pode ser devido à anoxia ou condições extremas de baixa oxigenação do fundo marinho. A síndrome pós-evento estaria registrada na porção superior do perfil (ambiente de shoreface distal), onde os bioclastos apresentaram uma reação fenotípica às condições desfavoráveis de crescimento individual (conulários, braquiópodes e moluscos), ou ainda, na seleção natural tanto de espécimens como de espécies de menor tamanho (produtores dos icnofósseis, ostracodes e trilobites), cujas necessidades alimentares seriam atendidas mesmo sob condições desfavoráveis, após o declínio da produção primária causada pela transgressão.

Segundo Urbanek (1993), fenótipos de tamanhos subnormais não implicam necessariamente mutação gênica ou especiação e, na maioria das vezes, é um estágio passageiro para a recolonização do substrato pelas antigas assembleias quando as condições ambientais forem normalizadas. Adicionalmente, os espaços ecológicos vazios podem ser ainda ocupados por imigrantes crípticos ou adventícios, o que, no caso em estudo, justificaria a presença marcante dos cefalópodes (evidenciados pelas abundantes estruturas de rolamento - roll marks). Estes, por não terem sido registrados em estratos inferiores, removem a suspeita de 'Efeito Lázarus', normalmente 
associado a essa situação (cryptic fauna), optando-se, no presente caso, pelo registro de uma fauna adventícia.

Segundo Twichett (2007), nota-se que, ao longo do registro geológico, fósseis preservados em fácies mais profundas são tipicamente menores do que seus coespećíicos de fácies mais rasas. Em faunas autóctones, as razões para esta preservação diferencial podem ser ambientais e, em faunas alóctones, as causas podem ser tafonômicas. Erlfeldt (2005) considera que a baixa produção primária em áreas bentônicas poderia invariavelmente ter um efeito adverso na população de braquiópodes e refletir no declínio do tamanho da população, do número de espécies e/ou no tamanho dos espécimens. Uma vez que condições de autoctonia a parautoctonia foram evidenciadas na ocorrência dos fenótipos subnormais aqui relatados, eles são considerados como a resposta morfotípica temporária para as acentuadas mudanças batimétricas predominantes na Formação São Domingos. Estas transgressões teriam modificado os fatores ambientais vigentes à época (incluso oxigenação, temperatura e produção primária), resultando nos fenótipos ali preservados.

Os novos achados, associados à interpretação paleoambiental dos depósitos perfilados, não deixam dúvidas quanto a um registro de mudança radical da composição, distribuição e abundância das tafocenoses na Formação São Domingos, conforme já destacado por Bosetti et al. (2010) e R. S. Horodyski, em sua dissertação. Os dados obtidos na seção colunar Sítio Wolff representam, da base para o topo, um momento de pré-crise biótica (durante o Neoeifeliano), seguido de um evento de extinção possivelmente relacionado ao evento KACAK (House, 1985, 2002). Este, por sua vez, é sucedido por um episódio (durante o Eogivetiano) caracterizado pelo aparecimento do Efeito Lilliput (sensu Urbanek, 1993), registrado pelos fenótipos subnormais de tamanho.

\section{CONCLUSÕES}

De acordo com as assinaturas tafonômicas obtidas, pode-se inferir que não houve transporte significativo dos bioclastos na seção Sítio Wolff, conferindo à tafocenose situação de autoctonia a parautoctonia. A análise taxonômica dos bioclastos indicou que os taxa ocorrentes compõem uma assembleia reliquiar da Província Malvinocáfrica, com invertebrados não malvinocáfricos associados. A variação litológica indica mudanças ambientais e físicas drásticas, com um acentuado pico transgressivo, que, possivelmente, foi o responsável pela crise biótica. A síndrome pós-evento é representada pela distribuição e abundância dos fenótipos de tamanhos subnormais ocorrentes no topo da seção. Fauna imigrante é atestada pela presença de marcas de rolamento (possivelmente cefalópodes) e presença marcante de Phycosiphon.

\section{AGRADECIMENTOS}

Os autores agradecem ao Conselho Nacional de Desenvolvimento Científico Tecnológico (CNPq PQ 480427/2007-0) pelo suporte financeiro. Os autores também agradecem aos pesquisadores Dr. Yngve Grahn (Universidade Estadual do Rio de Janeiro - UERJ e Petrobras) e Dra . Paula Mendlowicz Mauller (UERJ) pelas análises de microfósseis e Dr. Rafael Costa da Silva (Companhia de Pesquisa de Recursos Minerais - CPRM) pelo auxilio com os icnofósseis. Rodrigo Scalise Horodyski (141256/2010-9), Carolina Zabini (140659/2007-2)e Andressa Carla Penteado agradecem ao CNPq pelo auxílio financeiro.

\section{REFERÊNCIAS}

ASSINE, M. L. \& S. PETRI, 1996. Sequências e tratos deposicionais no pré-Carbonífero da Bacia do Paraná, Brasil. Anais do Simpósio Sul-americano do Siluro-Devoniano 357-361.

BERGAMASCHI, S. \& E. PEREIRA, 2001. Caracterização de sequências deposicionais de $3^{\text {a }}$ ordem para o Siluro-Devoniano na sub-bacia de Apucarana, Bacia do Paraná, Brasil. Ciência-TécnicaPetróleo. Seção Exploração de Petróleo 20: 63-72.

BOSETTI, E. P., R. S. HORODYSKI \& C. ZABINI, 2009. Lilliput Effect in the Malvinokaffric Realm? Boletim da Sociedade Brasileira de Paleontologia 10: 37-38.

BOSETTI, E. P., Y. GRAHN, R. S. HORODYSKI, P. M. MAULLER, P. BREUER \& C. ZABINI, 2010. An earliest Givetian "Lilliput Effect" in the Paraná Basin, and the collapse of the Malvinokaffric shelly fauna. Paläontologische Zeitschrift (2 July 2010). 
COPPER, P., 1977. Paleolatitudes in the Devonian of Brazil and the Frasnian-Famennian mass extinction. Palaeogeography, Palaeoclimatology, Palaeoecology 21: 165-207.

ERLFELDT, A., 2005. Brachiopod faunal dynamics during the Silurian Ireviken Event, Gotland, Sweden: 1-199. Lunds Universitet (Examensarbete i Geologi), Lund.

GAUGRIS, K. A. \& Y. GRAHN, 2006. New chitinozoan species from the Devonian of the Paraná Basin, south Brazil, and their biostratigraphic significance. Ameghiniana 43: 293-310.

GRAHN, Y., E. PEREIRA \& S. BERGAMASCHI, 2000. Silurian and Lower Devonian chitinozoan biostratigraphy of the Paraná Basin in Brazil and Paraguay. Palynology 24: 143-172.

HOUSE, M. R., 1985. Correlation of Mid-Palaeozoic ammonoid evolutionary events with global sedimentary perturbations. Nature 313: $17-22$

HOUSE, M. R., 2002. Strength, timing and cause of mid-Palaeozoic extinctions. Palaeogeography, Palaeoclimatology, Palaeoecology 181: $5-25$

ISAACSON, P. E., 1978. Paleolatitudes in the Devonian of Brazil and the Frasnian-Fammenian mass extinction. Coments: Palaeogeography, Palaeoclimatology, Palaeoecology 24: 359-362.

LANGE, F. W., 1967. Bioestratigraphic subdivision and correlation of Devonian in the Paraná Basin. Boletim Paranaense de Geociências 21-22: 63-98.

LANGE, F. W. \& S. PETRI, 1967. The Devonian of Paraná Basin. Boletim Paranaense de Geociências 22: 63-98.

LUCAS, S., 2001. Taphotaxon. Lethaia 34: 30.

MENDLOWICZ MAULLER, P., Y. GRAHN \& T. R. MACHADO CARDOSO, 2009. Palynostratigraphy from the Lower Devonian of the Paraná Basin, south Brazil, and a revision of contemporary chitinozoan biozones from western Gondwana. Stratigraphy 6: 313-332.

MILANI, E. J., J. H. G. MELO, P. A. SOUZA, L. A. FERNANDES \& A. B. FRANÇA, 2007. Bacia do Paraná. Boletim de Geociências da Petrobrás 15: 265-287.

MILLER, M. F. \& S. E. SMAIL, 1997. A semiquantitative field method for evaluating bioturbation on bedding planes. Palaios 12: 391-396.

PETRI, S., 1948. Contribuição ao estudo do Devoniano paranaense. Boletim da Divisão de Geologia e Mineralogia 129: 1-127.
READING, H. G. \& J. D. COLLINSON, 1996. Clastic coasts. In: H. G. READING (Eds.): Sedimentary Environment: 154-231. Blackwell Science, Oxford.

RICHTER, R., 1941. Devon: 31-43. Geologische Jahresberichte, Berlin.

RODRIGUES, S. C., M. G. SIMÕES \& J. M. LEME, 2003. Tafonomia comparada dos Conulatae (Cnidaria), Formação Ponta Grossa (Devoniano), Bacia do Paraná. Revista Brasileira de Geociências 33: 1-10.

SEILACHER, A., 2007. Trace Fossil Analysis: 1-226. Springer, Berlin.

SHIRLEY, J., 1965. The distribution of Lower Devonian faunas. In: E. A. M. NAIR (Ed.): Problems in palaeoclimatology: 255-261. Interscience, London.

SIMÕES, M. G. \& R. P. GHILARDI, 2000. Protocolo tafonômico/ paleoautoecológico como ferramenta nas análises paleossinecológicas de invertebrados: exemplos de aplicação em concentrações fossiliferas do Paleozóico da Bacia do Paraná, Brasil. Pesquisas 27: 3-13.

SIMÕES, M. G., S. C. RODRIGUES, J. M. LEME \& H. V. ITEN, 2003. Some Middle Paleozoic conulariids (Cnidaria) as possible examples of taphonomic artifacts. Journal of Taphonomy 1: 165-186.

SIMÕES, M. G., J. M. LEME \& S. P. SOARES, 2009 Systematics, taphonomy, and paleoecology of Homalnotid Trilobites (Phacopida) from the Ponta Grossa Formation (Devonian), Paraná Basin, Brazil. Revista Brasileira de Paleontologia 12: 27-42.

SOARES, S. P., M. G. SIMÕES \& J. M. LEME, 2008. O papel da fossilização e do intemperismo na sistemática de trilobitas Phacopida (Calmoniidae e Homalonotidae) do Devoniano da Bacia do Paraná, Brasil. Revista Brasileira de Paleontologia 11: 59-68.

TWICHETT, R. J., 2007. The Lilliput effect in the aftermath of the end-Permian extinction event. Palaeogeography, Palaeoclimatology, Palaeoecology 252: 132-144.

URBANEK, A., 1970. Neocucullograptinae n. subfam. (Graptolithina) - their evolutionary and stratigraphic bearing. Acta Palaeontologica Polonica 15: 163-388.

URBANEK, A., 1993. Biotic crises in the history of Upper Silurian graptoloids: A palaeobiological model. Historical Biology 7: 29-50.

WALKER, R. G. \& A. G. PLINT, 1992. Wave and storm dominated shallow marine systems. In: R. G. WALKER \& N. P. JAMES (Eds.): Facies Models - Response to sea level change: 219-238. Geological Association of Canada, Canadá.

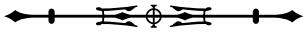


